\title{
DEVELOPMENT OF RAPID PIPE MOULDING PROCESS FOR CARBON FIBER REINFORCED THERMOPLASTICS BY DIRECT RESISTANCE HEATING
}

\author{
KAZUTO TANAKA*, RYUKI HARADA, TOSHIKI UEMURA, TSUTAO KATAYAMA \\ Department of Biomedical Engineering, Doshisha University, 1-3 Tatara-miyakodani \\ Kyotanabe, 610-0394, Kyoto, Japan \\ "ktanaka@mail.doshisha.ac.jp \\ HIDEYUKI KUWAHARA \\ Material Processing Technologies, 63-1-214 Echigoyashikicho, Fukakusa \\ Fushimi-ku, 612-8431, Kyoto, Japan
}

\begin{abstract}
To deal with environmental issues, the gasoline mileage of passenger cars can be improved by reduction of the car weight. The use of car components made of Carbon Fiber Reinforced Plastics (CFRP) is increasing because of its superior mechanical properties and relatively low density. Many vehicle structural parts are pipe-shaped, such as suspension arms, torsion beams, door guard bars and impact beams. A reduction of the car weight is expected by using CFRP for these parts. Especially, when considering the recyclability and ease of production, Carbon Fiber Reinforced Thermoplastics are a prime candidate. On the other hand, the moulding process of CFRTP pipes for mass production has not been well established yet. For this pipe moulding process an induction heating method has been investigated already, however, this method requires a complicated coil system. To reduce the production cost, another system without such complicated equipment is to be developed. In this study, the pipe moulding process of CFRTP using direct resistance heating was developed. This heating method heats up the mould by Joule heating using skin effect of highfrequency current. The direct resistance heating method is desirable from a cost perspective, because this method can heat the mould directly without using any coils. Formerly developed Non-woven Stitched Multi-axial Cloth (NSMC) was used as semi-product material. NSMC is very suitable for the lamination process due to the fact that non-crimp stitched carbon fiber of $\left[0^{\circ} / 45^{\circ} / 90^{\circ} /-45^{\circ}\right]$ and polyamide 6 non-woven fabric are stitched to one sheet, resulting in a short production cycle time. The use of the pipe moulding process with the direct resistance heating method in combination with the NSMC, has resulted in the successful moulding of a CFRTP pipe of $300 \mathrm{~mm}$ in length, $40 \mathrm{~mm}$ in diameter and $2 \mathrm{~mm}$ in thickness.
\end{abstract}

Keywords: Carbon fiber; thermoplastics resin; direct resistance heating.

\section{Introduction}

Due to the high-specific strength and high-specific stiffness, Carbon Fiber Reinforced Plastics (CFRP) are applied in various fields of application, such as aerospace and automobile industries. ${ }^{1}$ Within the automobile industry, in order to improve gasoline mileage of passenger cars, their weight has to be reduced for instance by using CFRP. ${ }^{2}$ 
Pipe-shaped components, such as the impact beam, door guard bar, suspension arm and torsion beam, are common vehicle structural components which are well suited to be made of CFRP in order to reduce the car weight. This has however not been applied widely yet, due to the expected high costs.

Currently, CFRP with a thermoset resin is used the most in automobile and aerospace industries. ${ }^{3}$ However, considering moulding time ${ }^{4}$ and recyclability, it is desirable to use thermoplastic resins instead. For the Carbon Fiber Reinforced Thermoplastics (CFRTP) pipe moulding process, rapid processing using the electromagnetic induction was developed. ${ }^{5}$ In the case of induction heating, an alternating current within a coil produces a magnetic field, which induces Eddy currents in the mould surface. However, this system requires a coil system for electromagnetic induction. To reduce the cost of production, the development of another system without complicated equipment is needed.

As heating methods for the heat treatment and welding of metals, induction heating and direct resistance heating are used. The advantages of direct resistance heating are rapid heating by the skin effect and the ability to heat without a coil. The here considered heating process allows the reduction of production cost. In our previous study, Nonwoven Stitched Multi-axial Cloth (NSMC) was developed as a moulding semi-product material for Carbon Fiber Reinforced Thermoplastics (CFRTP) products. ${ }^{6}$ NSMC, in which non-crimp stitched carbon fabric and non-woven resin fabric for matrix resin are stitched to one sheet, provides an easy production process and makes cycle times short.

In this study, the rapid pipe moulding process of CFRTP by means of direct resistance heating in combination with NSMC was developed. In addition, the electrical energy usage of induction heating and direct resistance heating methods was compared.

\section{Materials and experiment procedure}

\subsection{Materials}

NSMC was used as the moulding semi-product material. As shown in fig. 1 , polyamide 6 non-woven fabric was stitched to Carbon fabric in the process of manufacturing the noncrimp stitched fabric (NCF). This NSMC consists of non-crimp stitched carbon fabric at $\left[0^{\circ} / 45^{\circ} / 90^{\circ} /-45^{\circ}\right]$ with a weight per unit area of $240 \mathrm{~g} / \mathrm{m}^{2}$ and polyamide 6 non-woven fabric in the weight per unit area of $50 \mathrm{~g} / \mathrm{m}^{2}$. NSMC combines the matrix material and the reinforcing fibers into one sheet. It is very well applicable in the winding process.

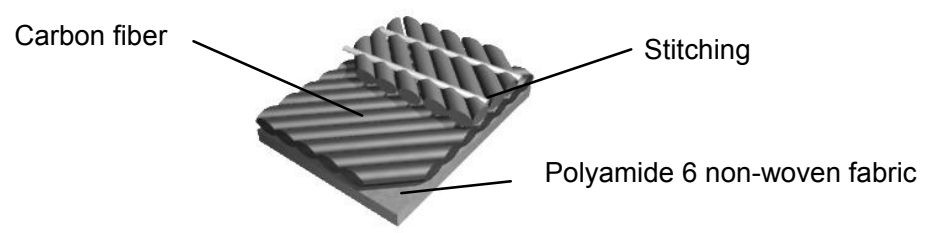

Fig. 1. Schematic drawing of Non-woven Stitched Multi-axial Cloth (NSMC). 


\subsection{Direct resistance heating}

Direct resistance heating and induction heating are commonly used for the heat treatment and welding of metals, as they are using Joule heating by the skin effect of highfrequency current. ${ }^{7-9}$ The polarization of induced current as shown in fig. 2 is called a skin depth. The skin depth $\delta$ is defined by the equation below, where $\rho$ is the electrical resistance, $f$ is the current frequency and $\mu$ is the absolute permeability. In this study, SUS430 was used for the inner mould owing to its high magnetic permeability.

$$
\delta=\sqrt{\frac{\rho}{\pi f \mu}}
$$

The rapid heating of mould surface is possible by applying this heating method to the moulding process of CFRTP. In this study, we focus on direct resistance heating without any coil.

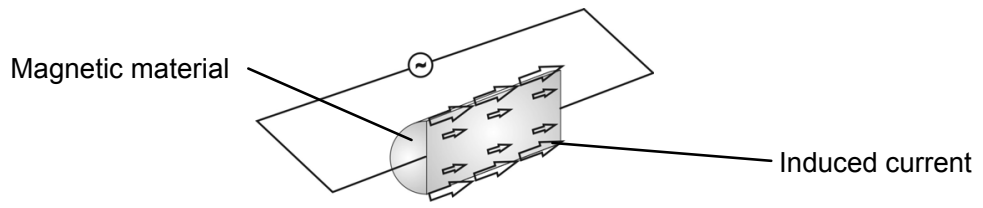

Fig. 2. Schematic drawing of skin effect.

\subsection{Moulding procedure of CFRTP pipe by direct resistance heating}

Fig. 3 is a schematic drawing of the pipe moulding process for CFRTP. A stainless steel round bar of $315 \mathrm{~mm}$ in length and $32 \mathrm{~mm}$ in diameter was used as the material for the inner mould. At first, a silicon rubber tube was wound around the inner mould to apply inner pressure to the NSMC. The NSMC was cut to a width of $300 \mathrm{~mm}$, and wound fourfold around the mould. After that, it was compressed by the outer mould using metal bands.

A high-frequency vacuum-tube oscillator with $30 \mathrm{~kW}$ maximum output and $185 \mathrm{kHz}$ current frequency was used. In this study, the inner mould was heated by the oscillator at $1 \mathrm{~kW}$ output. This device applies the electric current to both ends of the inner mould by attached electrodes. The temperature of the material contacting the outer mould was measured by thermocouples during the heating and cooling process.

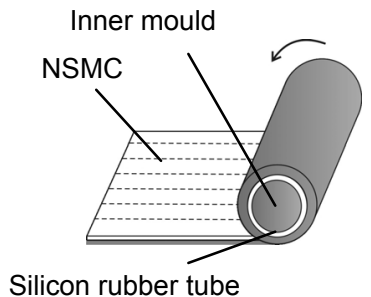

(a) Winding process.

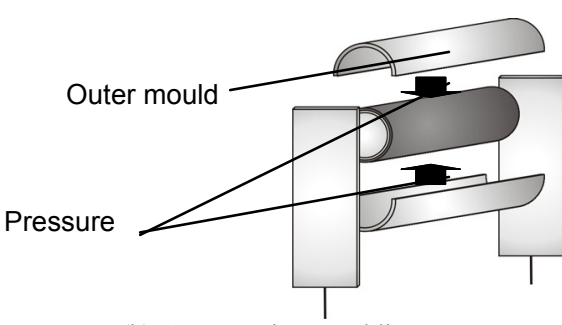

(b) Compression moulding process.

Fig. 3. Process of CFRTP pipe moulding. 


\subsection{Tensile test}

The length and width of the specimen for the tensile test were $230 \mathrm{~mm}$ and $10 \mathrm{~mm}$ respectively, cut from the moulded tube. The cross section of the specimen was an arclike shape and it was bonded to an aluminum tab using epoxy resin. The tensile test was conducted using a universal testing machine (Autograph AG-100kN, Shimadzu Co., Japan) and a video non-contact extensometer (DVE-100, Shimadzu Co., Japan) was used to measure the extension of specimen. The gauge length and displacement rate were $50 \mathrm{~mm}$ and $1.67 \times 10^{-5} \mathrm{~m} / \mathrm{s}$ respectively.

\subsection{Comparison of electrical energy}

The electrical energy usage of direct resistance heating and induction heating was compared. The electrical energy was calculated by using the following equation. $P$ is the output of oscillator and $t$ is the heating time.

$$
W=P t
$$

In this study, the electrical energy of direct resistance heating is calculated with the assumption that the maximum temperature at moulding is $230{ }^{\circ} \mathrm{C}$. The electrical energy of the induction heating system is calculated using the data of a reference. ${ }^{5}$

\section{Results and discussion}

\subsection{Evaluation of moulding}

Fig.4 is the temperature history during moulding process of the material right below the outer mould. In order to properly distribute the resin around the reinforcing fibers, after reaching the maximum temperature during moulding, the outer mould was clamped more tightly and the inner mould was reheated. Using the oscillator for heating, allows the temperature of the mould to rise to $230{ }^{\circ} \mathrm{C}$ in 420 seconds. Fig. 5 gives an overview of the moulded pipe. The CFRTP was moulded into a pipe shape without any remaining resin residues.

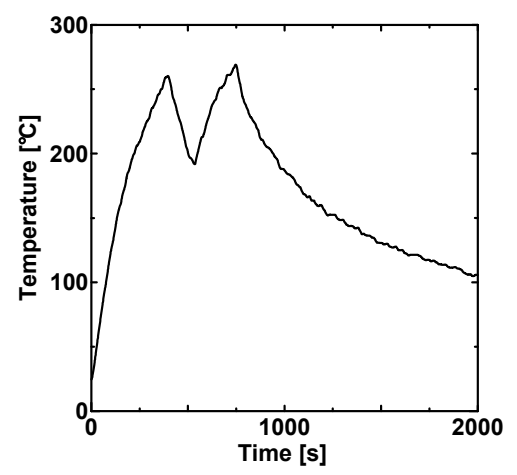

Fig. 4. Temperature history.

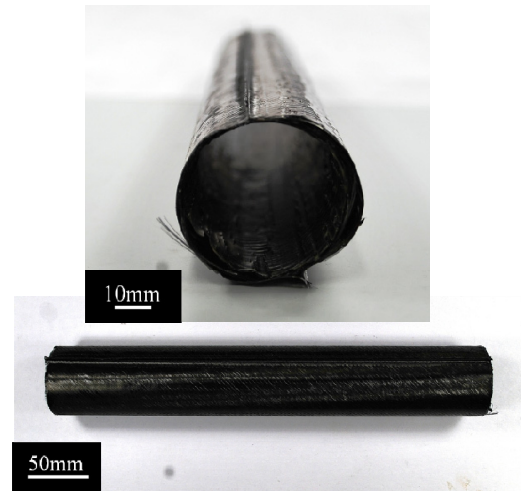

Fig.5.Cross section view and outer appearance of CFRTP pipe. 


\subsection{Results of tensile test}

The tensile strength and tensile modulus of CFRTP were $427 \mathrm{MPa}$ and $26.4 \mathrm{GPa}$ respectively. On the basis of tensile test, the specific strength and the specific stiffness of CFRTP were compared with lightweight metal materials such as a high strength steel ${ }^{10,11}$ and an aluminum alloy. ${ }^{12-14}$ In this study, the specific strength of CFRTP exceeded the specific strength of lightweight materials and the specific stiffness of CFRTP was approximately $80 \%$ of the specific stiffness of lightweight materials as shown in fig.6 and fig.7. Consequently, CFRTP moulded using direct resistance heating is expected to be a suitable replacement for lightweight metals in car components.

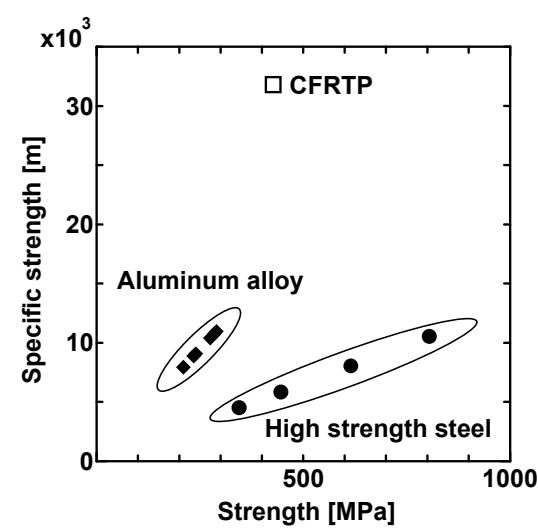

Fig. 6. Comparison of specific strength.

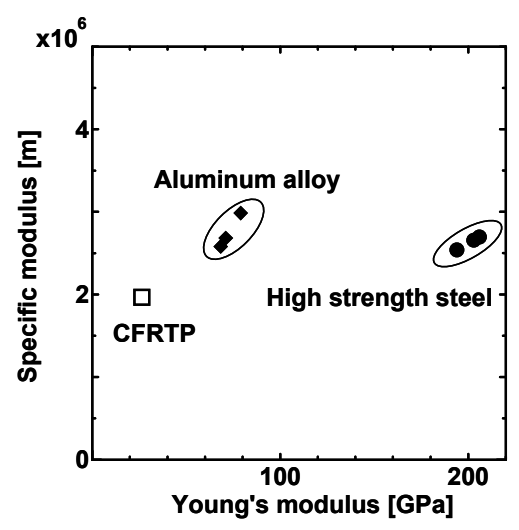

Fig. 7. Comparison of specific-stiffness.

\subsection{Comparison of electrical energy}

Table 1 shows powers, heating times and electrical energies of each heating method. The electrical energy required for direct resistance heating is approximately $15 \%$ of that required for the induction heating methods. The direct resistance heating enables heating with low energy loss. The reason for the low efficiency of the induction heating is the large amount of energy required to produce the magnetic field. Therefore, the direct resistance heating enables heating of the mould with less electrical energy, which is beneficial for cost reduction.

Table 1. Power and heating time of each heating method. ${ }^{5}$

\begin{tabular}{r|r|r|r}
\hline & $\begin{array}{r}\text { Power } \\
{[\mathrm{kW}]}\end{array}$ & $\begin{array}{r}\text { Heating time } \\
{[\mathrm{s}]}\end{array}$ & $\begin{array}{r}\text { Electrical energy } \\
{[\mathrm{kWh}]}\end{array}$ \\
\hline Induction heating & 100 & 30 & 0.83 \\
\hline Direct resistance heating & 1.0 & 420 & 0.12 \\
\hline
\end{tabular}




\section{Conclusions}

1) As NSMC containing non-crimp carbon fabric and non-woven matrix resin can make the laminating process simple, it is suitable as a material for the moulding of a CFRTP part.

2) The specific strength of CFRTP exceeded the specific strength of metal materials and the specific stiffness of CFRTP was approximately $80 \%$ of the specific stiffness of metal materials, therefore, CFRTP moulded by direct resistance heating is expected to be an alternative material for metal car components.

3) The electrical energy required by direct resistance heating is approximately $15 \%$ of that required by induction heating.

\section{References}

1. S. Birch, A materialistic industry, Aerospace Engineering, pp.22-25 (2004).

2. Y. Daisho, Perspectives on Future Motor Vehicle Technologies Associates with Environment and Energy, IATSS, Vol.33, No.3, pp.269-274 (2008).

3. K. Suzuki, S. Toyoda, A Sato, Y. Ueno and M. Okada, Development of a New Bending Method "PRB" for High Strength Steel Tube and Application of High Strength Steel Tubes for Automotive Parts, JFE GIHO, No.17, pp.52-58 (2007).

4. A.Nakai, Application of Fiber Reinforced Plastics to Advanced Vehicle for Energy Saving Society, SEN'I GAKKAISHI, Vol.65, No.1, pp.31-32 (2009).

5. D.Perrier and J.Feigenblum, Rapid processing of tubular parts made of thermoplastic composites, JEC-Composites, pp.68-70 (2008).

6. K. Tanaka, N. Kohashi, Y. Kinoshita, T. Katayama and K. Uno, Compression molding of carbon fiber reinforced thermoplastics using non-woven stitched multi-axial cloth by means of induction heating system, Journal of Society of Material Science, Vol.58, No.7, pp.642-648 (2009).

7. M.Ishiguro, S. Maki and K. Mori, Improvements in mechanical properties of Al-Mg-Si alloy sheets by resistance heat-treatment, Journal of Japan Institute of Light Metals, Vol.54, No.12, pp.562-566 (2004).

8. M. Dube, P. Hubert, A. Yousefpour and J. Denault, Resistance welding of thermoplastics composites skin/stringer joints, Composites: Part A 38, pp.2541-2552 (2007).

9. K.Hamada, K. Isaka, D. Doi, Y. Yonemitsu and S. Iwasaki, Application of Direct Resistance Heating for Stainless Steel/Aluminum Clad Manufacturing Process, The Iron and Steel Institute of Japan, Vol.88, No.2, pp.16-22 (2002).

10. Y. Tanaka and S. Fujita, Forecast of the Manufacturing Technology of High Strength Steel Sheets for Light Weight Automobile Bodies, JFE GIHO, No.16, pp.1-5 (2007).

11. Y. Tanaka, T. Urabe and Y. Nagataki, New High Strength Steel for Exposure Panels -High Strength Steel Having Excellent Press Formability, Superior Surface Precision after Pressforming and Uniform Surface Appearance-, JFE GIHO, No.4, pp.15-21 (2004).

12. T. Masuda, M. Tanaka, H. Toda, T. Kobayashi and L. Wang, Stress triaxiality effect on dynamic tensile properties in a 6061-T6 aluminum alloy, Journal of Japan Institute of Light Metals, Vol.54, No.5, pp.175-181 (2004).

13. K. Ogawa, Impact tensile characteristics of 6061-T6 aluminum alloy, Journal of Japan Institute of Light Metals, Vol.51, No.3, pp.175-181 (2001).

14. T. Inaba, H. Yamashita, Y. Takebayashi, T. Minoura and S. Sasabe, Aluminum Product Application Technologies for Automobiles, KOBE STEEL ENGINEERING REPORTS, Vol.55, No.2, pp.66-74 (2005). 